\title{
Comunicação Organizacional e Relações Públicas no Brasil são singulares?
}

\author{
Do Organizational Communicational and Public \\ Relations in Brazil have singular features?
}

\author{
¿Comunicación Organizacional y Relaciones \\ Públicas son singulares en Brasil?
}

Maria do Carmo Reis

- Doutora em Business Studies and Industrial Relations pela Warwick Business School da Warwick University (Inglaterra)

- Mestre em Administração pela Universidade Federal de Minas Gerais (UFMG)

- Especialista em Comunicação Rural e Comunitária pela Universidade Federal de Pernambuco (UFPE)

- Graduada em Relações Públicas pela UFMG

- Professora do Departamento de Comunicação Social da UFMG, na área de Comunicação das Organizações

- É membro do Conselho Consultivo da Associação Brasileira de Pesquisadores de Comunicação Organizacional e de Relações Públicas (Abrapcorp)

- Principais interesses de pesquisa: epistemologia da comunicação organizacional e gestão estratégica da comunicação das organizações, especialmente em contextos de mudança organizacional estratégica

- mcreis@ufmg.br 
O artigo trata da posição da autora em relação à discussão identitária sobre Relações Públicas e Comunicação Organizacional no Brasil. Relata o contexto de emergência dessa discussão, as questões colocadas, identifica a abordagem mainstream e apresenta e defende o ponto de vista de que há sobre o assunto uma interpretação brasileira que é distintiva.

PALAVRAS-CHAVE: RELAÇÕES PÚBLICAS • COMUNICAÇÃO ORGANIZACIONAL • FÓRUM ABRAPCORP

\section{Abstract}

This article concerns the author's position in relation to discussion of the identity of the fields of Public Relations and Organizational Communication in Brazil. It presents the context of emergency for this discussion and the questions raised, while identifying the mainstream approach and defending that there is a distinctive Brazilian construal of this issue.

KEYWORDS: PUBLIC RELATIONS • ORGANIZATIONAL COMMUNICATION・ABRAPCORP FORUM

Resumen

Se expone la posición de la autora acerca de la discusión identitaria sobre Relaciones Públicas y Comunicación Organizacional en Brasil. Se relatan el contexto del surgimiento de esta discusión y las cuestiones planteadas; se identifica el abordaje mainstream; y se presenta y se defiende el punto de vista de que hay una interpretación brasileña distintiva de este asunto.

PALABRAS CLAVE: RELACIONES PÚBLICAS • COMUNICACIÓN ORGANIZACIONAL • FÓRUM ABRAPCORP 
C omunicação Organizacional e Relações Públicas, no Brasil, são diferentes do que caracteriza a literatura especializada anglo-saxônica, que é a hegemônica? Caso sejam, o que dá a elas essa distinção? Essas questões começaram a ganhar os fóruns públicos de discussão em consequência do convite, feito à Compós, em 2005, pelo Conselho Nacional de Desenvolvimento Científico e Tecnológico (CNPq) para que ela se envolvesse na discussão da proposição de uma nova tabela de áreas de conhecimento para uso comum das agências de fomento brasileiras. A tabela vigente desde 1973 estava sendo avaliada como não mais correspondendo à realidade dos campos de conhecimento instituída no País. Urgia o desenvolvimento de uma nova tabela que desse visibilidade a campos de conhecimento que haviam surgido, a arranjos de fusão/realocação/desmembramento/extinção/alteração de nomenclatura de áreas de conhecimento, de tal forma que o pesquisador, ao solicitar fomento, conseguisse indicar claramente onde se situava a contribuição do seu trabalho em termos de conhecimento a ser produzido.

Tornando curta uma história que é longa, vale dizer que, a certa altura das discussões, desapareceu, da proposta da Compós para a área de Comunicação, a subárea que, sob qualquer rótulo que fosse, fizesse referência à produção de conhecimento específico sobre a comunicação das/nas/no contexto das (práticas das) organizações (empresariais, governamentais/do terceiro setor). A direção da Compós, à época, afirmou ter sido um lamentável lapso.

Olhando retrospectivamente, não posso deixar de reconhecer que esse incidente teve efeito muito positivo em termos de fomentar a mobilização dos estudiosos que se identificavam com essa subárea. Veio de Minas Gerais o primeiro grito, sob a forma de uma carta-manifesto assinada por mim e por mais onze colegas de diferentes universidades e centros universitários mineiros. Várias ações se seguiram, inclusive a decisão de criar uma associação dos estudiosos da área ${ }^{1}$, o que veio a ocorrer no ano seguinte. Como parte desse debate, em 19 de maio de 2005, Margarida K Kunsch produziu um documento, em que afirmava:

Contamos com cerca de 211 dissertações de mestrado e 42 teses de doutorado em Comunicação Organizacional. Em Relações Públicas contamos com 107 dissertações de mestrado e 16 teses de doutorado. [...] No Núcleo de Pesquisa em Comunicação Organizacional e Relações Públicas [da Intercom] [...] de 1992 a 2003 foram apresentados cerca de 207 trabalhos e em 2004 [ocorreu o lançamento da primeira revista acadêmico-científica especializada da área] Organicom. [...]. Estudos realizados tanto no âmbito acadêmico quanto na esfera do mercado profissional têm sinalizado que as interfaces entre essas áreas são uma realidade no Brasil (grifo meu).

1 Para a história da Associação Brasileira de Pesquisadores de Comunicação Organizacional e de Relações Públicas (Abrapcorp), ver http://www.abrapcorp.org.br. 
Apesar de, nessa citação, Kunsch caracterizar Comunicação Organizacional e Relações Públicas como áreas distintas - mas "com interface" -, historicamente, no Brasil, Relações Públicas, Comunicação Organizacional, Comunicação Empresarial, Comunicação Corporativa, Comunicação Institucional foram termos utilizados quase que indistintamente, muitas vezes, até mesmo em um único parágrafo, como se usam sinônimos para evitar repetição de termos. O fato é que, na literatura nacional especializada, por muitos anos, o termo genérico adotado, em especial quando se fazia referência a práticas de agenciamento comunicacional institucional, era "Relações Públicas". Aproximadamente por volta de meados dos anos 1980, esses outros termos começaram a ser utilizados alternativamente, quase que como "preferência pessoal" do autor; não parecia haver preocupação em se esclarecer se eles eram apenas sinônimos, se expressavam diferentes saberes (e, consequentemente, diferentes olhares em termos de área de conhecimento) ou ainda, quem sabe, se seriam apenas abordagens distintas de uma mesma questão.

O debate de 2005 também deu visibilidade a questões que até então haviam passado despercebidas: era sabido por nós que, na tabela de 1973, o termo Comunicação Organizacional não existia em nenhum lugar, sob nenhuma categoria (o que é compreensível)2 e que existia, sob a área de "Comunicação", a subárea de "Relações Públicas e Propaganda" (!). O que uma boa parte de nós não havia notado é que Relações Públicas também constava dessa tabela como área independente, sob a categoria "Outros", na qual eram listadas áreas de conhecimento cuja afiliação em termos de área-mater, em 1973, não era clara; isso já seis anos passados da regulamentação da profissão, que a caracterizou formalmente como especialidade do campo da Comunicação. A dúvida do $\mathrm{CNPq}$ seria talvez devida ao fato de que, como já relatei em trabalhos anteriores, no Brasil, as escolas de Administração foram pioneiras na oferta de formação profissional em Relações Públicas? O debate trouxe à tona essas várias questões que, em uma dinâmica de reflexividade dos estudiosos da comunicação das organizações, ressuscitaram debates identitários que foram estimulados e sustentados pela Abrapcorp por meio do Fórum sobre as Bases Conceituais de Comunicação Organizacional e de Relações Públicas. Este trabalho é uma síntese de meu posicionamento nesse fórum.

\section{0 contexto}

Em 2005 o Brasil já havia retornado ao regime democrático fazia vinte anos; desde então, o País já havia se globalizado, a academia havia retomado e ampliado o acesso livre e irrestrito à literatura especializada produzida nos circuitos internacionais ${ }^{3}$ e a sociedade civil brasileira havia desenvolvido substancial-

2 Para uma melhor compreensão do surgimento da Comunicação Organizacional no Brasil, ver Reis (2009a, 2009b).

3 Além do fim da censura na importação de literatura especializada, obtido com o fim da ditadura militar, 
mente suas frentes de organização e sua força enquanto voz. O movimento de inserção das organizações empresariais na co-responsabilização pelos problemas sociais do país já havia sido institucionalizado como parte do jogo competitivo de sobrevivência empresarial e havia ganhado visibilidade através da adoção de políticas institucionais de "responsabilidade social empresarial" 4 . Afinal, como afirma o Instituto Ethos, importante liderança nacional nesse campo,

as enormes carências e desigualdades sociais [...] [levaram] a sociedade brasileira [a] espera[r] que as empresas cumpram um novo papel no processo de desenvolvimento: sejam agentes de uma nova cultura, sejam atores de mudança social, sejam construtores de uma sociedade melhor.

Esse contexto influenciou profundamente, dinamizando-as, as práticas de agenciamento comunicativo das organizações, particularmente das empresariais, instituindo e potencializando práticas de comunicação integrada que, nesse novo contexto, buscaram ganhar caráter estratégico (KUNSCH, W., 2006). Foi com esse pano de fundo que o uso do termo "Comunicação Organizacional" começou a ganhar visibilidade no discurso de acadêmicos, profissionais e empresas brasileiros, mas ainda sem clareza se expressava ou não uma área (nova?) específica de conhecimento. O debate de 2005 fomentou a busca de resposta às questões: afinal de contas, Relações Públicas e Comunicação Organizacional são uma mesma coisa? Se não, qual é a diferença e a relação entre ambas, já que há o interesse comum na comunicação no contexto das práticas organizacionais?

0 meu ponto de vista

Sei que em vários países e também na literatura internacional anglo-saxônica, que é a hegemônica em termos globais, Comunicação Organizacional e Relações Públicas são áreas de conhecimento distintas em termos de afiliação histórica, de conteúdo e na relação acadêmico versus profissional. Mas tenho as minhas dúvidas sobre se essa diferença marcante pode ser percebida aqui no Brasil, apesar de, atualmente, nós, pesquisadores, estarmos sendo chamados, pelos nossos próprios pares, a nos posicionarmos em termos de com qual dessas áreas nos identificamos. Seria isso decorrente de implicân-

desde 2004 a Capes havia viabilizado, para as universidades e instituições de pesquisa públicas federais, 0 acesso on-line gratuito aos periódicos acadêmico-científicos de maior renome, em termos mundiais, nas principais áreas de conhecimento. Hoje "268 instituições de ensino superior e de pesquisa em todo o País têm acesso [...] aos textos completos de artigos [...] de mais de 15.475 revistas internacionais, nacionais e estrangeiras, e 126 bases de dados com resumos de documentos em todas as áreas do conhecimento (http://www.periodicos.capes.gov.br/portugues/index.jsp).

4 No Brasil, o movimento de valorização da responsabilidade social empresarial ganhou forte impulso na década de 1990, pela ação de Ong's, institutos de pesquisa e empresas sensibilizadas para a questão. 0 trabalho do Instituto Brasileiro de Análises Sociais e Econômicas (Ibase), e do Instituto Ethos têm destaque nesse esforço de implementação e disseminação da responsabilidade social empresarial no Brasil. 
cias corporativas com o fato de as Relações Públicas serem, aqui, profissão regulamentada? Preocupações da ordem do epistemológico não devem se misturar com esforços de reserva de mercado que acabam por delimitar uma área de conhecimento a competências técnicas, impedindo uma abordagem mais holística dos objetos comunicacionais.

Nesse contexto, avalio que, para nós, buscar definições (novas?) para essas duas áreas é menos importante do que procurar caracterizar como essas áreas se configuram, no Brasil, em termos teórico-conceitual e de prática empírico-profissional. Essa caracterização, sim, quando feita, permitirá o desenvolvimento de uma interpretação brasileira do que é Relações Públicas e Comunicação Organizacional aqui no Brasil. Sou contra brasileirismos per se, mas a minha percepção é de que, no Brasil, eles não obedecem aos padrões de diferenciação "tradicionais".

Acredito que há uma interpretação brasileira de Relações Públicas e Comunicação Organizacional que é diferente da perspectiva mainstream e que tem por característica central a simbiose do que é entendido, nessa literatura, como constituindo essas duas áreas. É uma comunicação das organizações que busca ser situada política, econômica e culturalmente no Brasil contemporâneo e no conceito do que sejam organizações socialmente responsáveis, inclusive em relação aos problemas sociais do País. Essa "comunicação das organizações" busca, na teoria e na prática, construir uma visão comunicacional holística, estratégica, humanizada e dialógica das organizações e de suas relações.

Creio que há um olhar distintivamente nosso sobre essa área unificada e que tem as seguintes características, identificadas por meio de minhas pesquisas: 1) a prática profissional marcando fortemente a teorização; 2) a preocupação com a construção de um lugar de fala comunicacional; 3) a procura de uma compreensão holística, mas também crítico-estratégica dos relacionamentos comunicativos das organizações, 4) a busca, por parte dos agentes comunicacionais, de construção de diálogo e de mecanismos de participação a partir da experiência relacional histórica com cada grupo específico de stakeholders, 5) o esforço no que se refere à interpretação e formação de sentido para o trabalhador; 6) o encontro de respostas consistentes, coerentes e social e politicamente responsáveis a anseios reais dos stakeholders, 7) uma visão que não distingue organizações de primeiro, segundo e terceiro setores quanto a serem todas agentes interlocutores que têm demandas, necessidades e interesses comunicacionais.

Na compreensão que tenho do que seja essa comunicação das organizações e que é marcada pelo meu lugar de fala que é a comunicação, comunicação e organizações revelam-se teoricamente como indissociáveis, produzindo, no âmbito do conhecimento, uma zona de interseção entre o campo da Comunicação e o dos Estudos Organizacionais em que a reflexão sobre o comunicar não consegue ser feita sem a sua situação no contexto organizacional (em suas várias dimensões). A busca de compreensão do fenômeno comunicacional 
descolado do contexto em que ocorre ou que o aciona levaria à redução e até ao desaparecimento do objeto. Nesse sentido, a busca de compreensão teórica desse objeto requer a construção de um olhar comunicacional construído de bases teóricas de interface.

Apesar de a nossa subárea ser, no Brasil, muitas vezes, criticada por pares de outras subáreas da Comunicação por produzirem, em termos de investigações empíricas, muitos estudos de caso, acredito que seja esse olhar sobre a realidade empírica do que ocorre aqui em termos de prática e reflexões orientadoras dessa prática que vai nos auxiliar a compreender melhor o que seja a interpretação de Relações Públicas-Comunicação Organizacional vigente no Brasil.

\section{Referências}

KUNSCH, Waldemar Luiz. Do mercado à academia: as relações públicas em seu primeiro centenário (1906-2006). Revista Brasileira de Ciências da Comunicação, v. 29, n. 2, p. 55-87, jul.-dez. 2006.

REIS, Maria do Carmo. A construção de uma identidade disciplinar e de um corpus teórico para os estudos de comunicação organizacional e relações públicas no Brasil. In: KUNSCH, Margarida M. Krohling (Org.). Comunicação organizacional e relações públicas: campos acadêmicos e aplicados de múltiplas perspectivas. São Caetano do Sul, SP: Difusão, 2009.

The social, political and economic context in the development of organizational communication in Brazil. Management Communication Quarterly, v. 22, n. 4, p. 648-654, May 2009. 